\title{
Residual Stresses Due to Electron Beam Butt Welding of a
}

\section{0. $32 \%$ Plain Carbon Steel*}

by

\section{R. PRÜMMER**}

(Received Aug. 16, 1968)

\section{Introduction}

It is well known that the properties of material are not only affected by its microstructure, but also by the presence of residual stresses. Therefore, residual stress determinations have been of interest in the last years within many investigations. Welding residual stresses are stresses that remain in the material after uneven cooling so that localized plastic deformation can occur. When a superposition of loading stresses with residual stresses occurs, the yield stress in special parts of a specimen can be reached even when the nominal loading stress is far beyond it. The strength of weldments can be influenced in a deleterious manner.

This paper is concerned with residual stresses in steel due to electron beam butt welding. As the bead in such weld-joints is small in shape, steep stress gradients are to be expected. Therefore mechanical methods like the Mathar-method ${ }^{1)}$ are not suitable for stress determination. The X-ray method not only allows stress determinations within small regions of the specimen but also has the advantage to be a nondestructive one.

\section{Basics}

The X-ray method ${ }^{22}$ of stress measurement is based on the determination of variation of lattice spacings in crystalline aggregates. Compared to mechanical strain measurements it is also possible to measure strains in directions perpendicular to the specimen's surface and under angles to the surface normal up to about $65^{\circ}$.

The principle is shown in Fig. 1 for the film method.

An X-ray beam with X-rays of wavelength $\lambda$ is incident on the specimen's surface in a plane given by the stress $\sigma_{R}$ to be determined and the specimen's surface normal SN inclined at an angle $\psi_{0}$ against the latter. At suitable lattice planes of the polycrystalline material reflection occurs and gives rise to interference lines on an X-ray film adjusted perpendicular to the primary $\mathrm{X}$-ray beam. The upper interference in Fig. 1 has its origin in diffracting lattice planes inclined at angle $\psi_{1}=\psi_{0}-\eta$ (where $\eta=90^{\circ}-\vartheta, \vartheta=$ Braggangle). The lower interference has its origin from lattice planes inclined at $\psi_{2}=\psi_{0}+\eta$. The

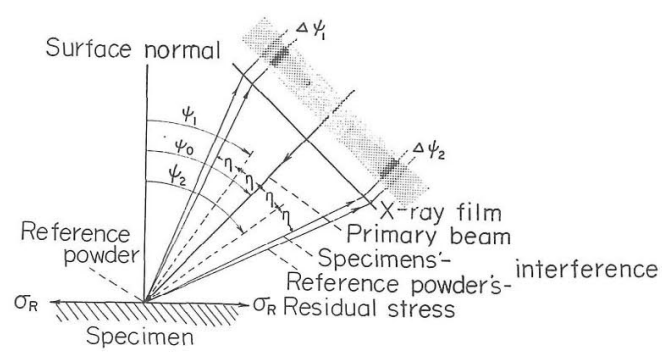

Fig. 1. Principle of X-ray stress measurement by film method. displacement of the specimen's interference lines is a measure of the lattice strain. In order to determine it exactly the distance $\Delta_{\psi_{i}}$ to the interference line of a suitable reference powder is measured. At a constant distance of the film from the irradiated specimen's area the relation

$$
\left(\Delta_{\psi_{i}}-\Delta_{0}\right) \cdot c=\varepsilon_{\psi_{i}}
$$

is valid, where $\Delta_{0}$ is the distance between the specimen's and reference powder's interference line in a stress free state and $c$ is a constant, depending from both the Bragg-angle of the specimen's and reference powder's interference. One exposure delivers two strain values $\varepsilon_{\psi_{i}}$ at different inclination $\psi_{i}$.

The equation relating the residual stress $\sigma_{R}$ of a biaxial stress system with $\varepsilon_{\psi}$ is given by

$$
\varepsilon_{\psi}=\frac{1}{2} S_{2} \sigma_{R_{R}} \sin ^{2} \psi+s_{1}\left(\sigma_{1}+\sigma_{2}\right)
$$

* 原稿受理 昭和43年 8 月16日

** Institut für Werkstoffkunde I, University of Karlsruhe, Germany. 
where the Voigt-constants are related to the elastic modulus $E$ and Poisson's ratio $\nu$ in the following manner :

$$
\begin{gathered}
\frac{1}{2} s_{2}=\frac{\nu+1}{E} \\
s_{1}=-\frac{\nu}{E}
\end{gathered}
$$

$\sigma_{1}$ and $\sigma_{2}$ are the principal residual stresses of the plane residual stress state and $\sigma_{R}=\sigma_{1} \cos ^{2} \varphi+$ $\sigma_{2} \sin ^{2} \varphi$ with $\varphi=\nless\left(\sigma_{1}, \sigma_{R}\right)$. When strain measurements are performed at different $\psi$-angles at $\varphi=0$ then $\sigma_{R}=\sigma_{1}$. For stress determinations four strain values $\varepsilon_{\psi i}$ at different inclination $\psi_{i}$ have proved to give a good accuracy. A plot of $\varepsilon_{\psi_{i}}$-values $v s_{0} \sin ^{2} \psi_{i}$ gives a linear relationship. The slope of it is proportional to $\sigma_{R}$ :

$$
\frac{\partial \varepsilon_{\dot{\varphi}}}{\partial \sin ^{2} \psi}=\frac{1}{2} S_{2} \sigma_{R}
$$

The intersection of the mean square line with the ordinate on the other hand is a measure for the sum of the principal stresses :

$$
\varepsilon_{\psi=0}=s_{1}\left(\sigma_{1}+\sigma_{2}\right)
$$

\section{Experiments}

Two steel specimens of a plain carbon steel with $0.32 \% \mathrm{C}$ of dimensions $5 \times 8.3 \times 40 \mathrm{~mm}^{3}$ were annealed at $700^{\circ} \mathrm{C}$ for two hours in a vacuum stove with furnace cooling. The way they were butt welded is shown in the left of Fig. 2. The electron beam welding conditions were $150 \mathrm{kV}$ accelerating voltage, $6 \mathrm{~mA}$ current and a velocity of the specimen perpendicular to the electron beam of $10 \mathrm{~mm} / \mathrm{sec}$. Fig. 3 shows the photomacrography of the cut welded specimen

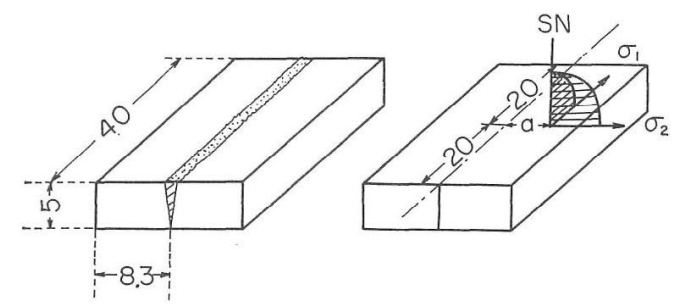

Fig. 2. Shape of electron beam butt welded steel specimen and location and planes, where lattice strain measurements were performed.

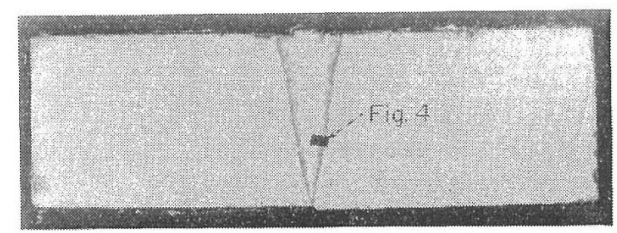

Fig. 3. Photomacrography of the electron beam butt welded specimen, etched with adler's reagent $(\times 10 \times 1 / 3)$.

in 10-fold magnification. The groove angle of the weld-bead is about $23^{\circ}$. Fig. 4 shows the structure of the bead. It is martensitic within the bead, and ferritic-pearlitic in the base material.

Residual stress measurements were performed at the upper and lower side of the welded specimen. The biaxial stress-state at the surface was determined in the middle of the specimen at different distances $\alpha$ from the bead in longitudinal and transverse direction. The planes in which lattice strain measurements were made for the determination of $\sigma_{1}$ and $\sigma_{2}$ are shown in Fig. 2 on the right. The lattice strain measurements occured with $\mathrm{Cr}-\mathrm{K} \alpha-$ radiation, the primary beam having a diameter of $0.3 \mathrm{~mm}$. The lattice spacings of $\{211\}$-planes of the ferrite were recorded. As a calibrating substance chromium powder was used giving rise to

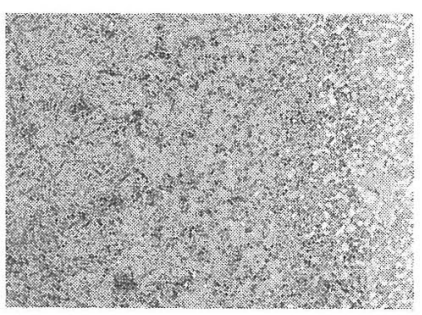

Fig. 4. Section of the bead of Fig. 3, showing the structure of the bead and the base material, etched with alcoholic nital $(\times 200 \times 2 / 5)$. a $\{211\}$-interference line near that of the specimen's one. In Fig. 1 such an exposure is shown. The lattice strains were calculated after equation (1), the residual stresses after equations (3) and (4). In order to take the influence of elastic anisotropy ${ }^{3)}$ of ferrite and the influence of heterogenity on the stress-lattice-strain relationship into account, the $\mathrm{X}$-ray elastic constants $1 / 2 s_{2} x=4.7 \times 10^{-5}$ and $s_{1} x=1.0 \times 10^{-5} \mathrm{~mm}^{2} / \mathrm{kg}$ for the investigated steel with $0.32 \% \mathrm{C}$ were used, which were determined in earlier studies ${ }^{4}$. As in each point of the 
specimen the stresses $\sigma_{1}$ and $\sigma_{2}$ were determined from the slopes of lattice strain distributions vs. $\sin ^{2} \psi$ in two perpendicular planes (Fig. 2, right), there existed a good control in accuracy, as their sum has to agree with that obtained from equation (4).

\section{Results}

Fig. 5 gives as an example the lattice strain distributions, which were obtained on the upper side of the specimen in the center of the weldment at $\mathrm{a}=0$ in $\alpha$ longitudinal and transverse plane, respectively. From the slopes of the mean square lines a compressive residual stress of $\sigma_{1}=-37$ in longitudinal direction and of $\sigma_{2}=-52 \mathrm{~kg} / \mathrm{mm}^{2}$ in transverse direction is obtained. From the intersection of the mean square lines with the ordinate the sum of the principal residual stresses amounts to $-85 \mathrm{~kg} / \mathrm{mm}^{2}$. The agreement is good. During the course of these investigations no greater deviations in the sum of the principal residual stresses than \pm $5 \mathrm{~kg} / \mathrm{mm}^{2}$ were obtained.

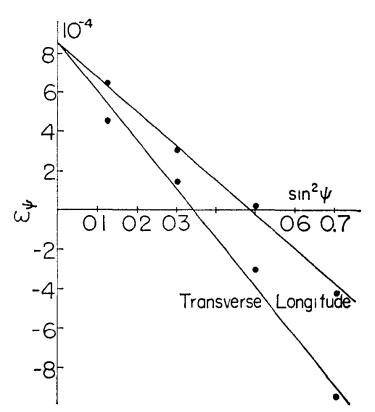

Fig. 5. Residual lattice strain distributions obtained on the specimens upper side in the center in longtidudinal and transverse direction with $\mathrm{Cr}$ $\mathrm{K} \alpha$-radiation at $\{211\}$-lattice planes.

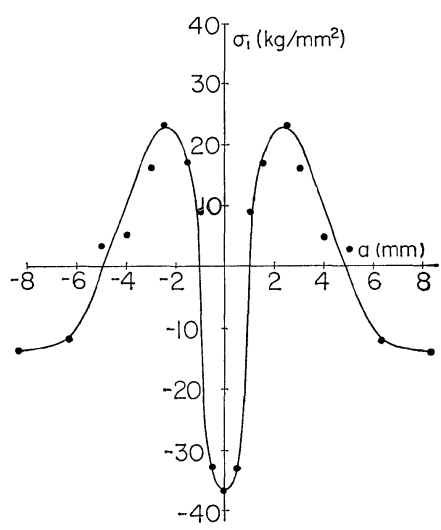

Fig. 6. Residual stress $\sigma_{1}$ in longitudinal direction vs. distance $\alpha$ from the center of the bead, upper side.

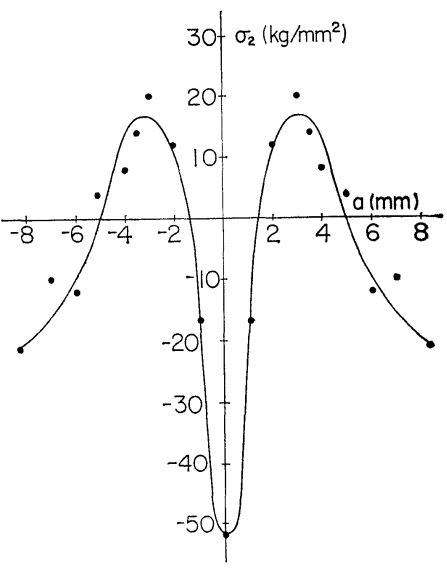

Fig. 7. Residual stress $\sigma_{2}$ in transverse direction $v s$. distance $\alpha$ from the center of the bead, upper side.

In Fig. 6 and Fig. 7 the residual stresses $\sigma_{1}$ and $\sigma_{2}$ of the upper side of the welded specimen are drafted vs. the distance $\alpha$ from the bead. In both cases the compressive stresses in the center of the bead become tensile character at a distance of about $1 \mathrm{~mm}$ and change their sign again at a distance of about $5 \mathrm{~mm}$ from the bead. Both the compressive stresses in the center and at the edge $(a=8.3 \mathrm{~mm})$ of the specimen are of greater amounts in the transverse direction whereas the tensile maximum at $a=2.5 \sim 3 \mathrm{~mm}$ is greater in longitudinal direction.

The residual stresses obtained in the transverse and longitudinal direction of the lower side of the specimen are illustrated in Fig. 8 and Fig. 9. Their maximum values are smaller in amount. In the center of the bead a compressive stress of $-7 \mathrm{~kg} / \mathrm{mm}^{2}$ is obtained in longitudinal direction, whereas in transverse direction a tensile stress of the same amount is present. With increasing distance from the center of the bead a change in sign of the residual stresses occurs three times in longitudinal and twice in transverse direction.

At the specimen's edge tensile stresses are measured in both directions.

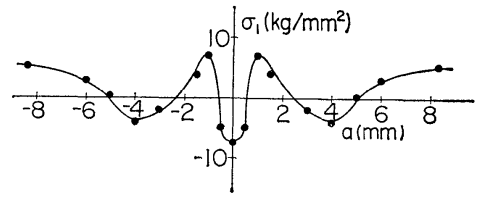

Fig. 8. Residual stress $\sigma_{1}$ in longitudinal direction $v$ s. distance $\alpha$ from the center of the bead, lower side.

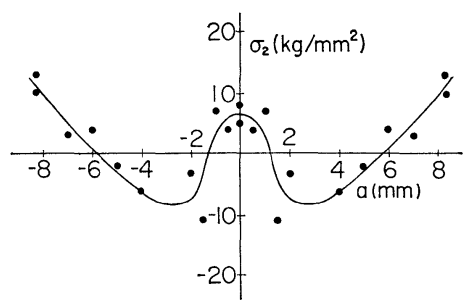

Fig. 9. Residual stress $\sigma_{2}$ in transverse direction $v s$. distance $\alpha$ from the center of the bead, lower side. 
Vickers' hardness measurements which were performed across the weld of the cut specimen with a load of $1 \mathrm{~kg}$ lasting $10 \mathrm{sec}$. are shown in Fig. 10 and Fig. 11 for distances from the upper side of the specimen of 0.7 and $3 \mathrm{~mm}$. Due to the martensitic structure of the bead there occurs an increase in hardness from 155 in the base material to 615 in the bead of the welded specimen. This result is in accordance with measurements of Steigerwald and Schulz ${ }^{7}$ at two plates of different steel with 0.35 and $0.48 \% \mathrm{C}$ butt welded by electron beam welding.

\section{Discussion of Results}

Up to now to the knowledge of the author there do not exist any residual stress measurements

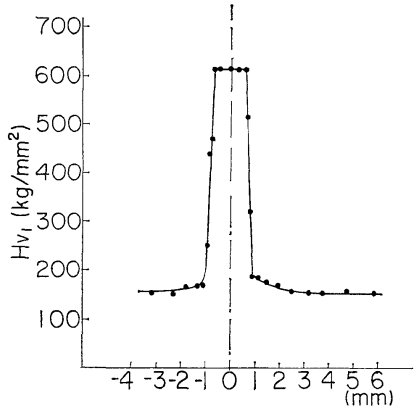

Fig. 10. Vicker's hardness across the weld of the electron beam welded specimen, $0.7 \mathrm{~mm}$ below upper side.

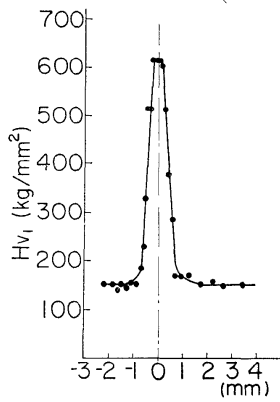

Fig. 11. Vicker's hardness across the weld of the electron beam welded specimen, $3 \mathrm{~mm}$ below upper side. at electron beam butt welded steel specimen on the upper and lower side of the specimen as well which would allow a comparison with the present investigations. The significance of these are outlined, when the amounts of the welding residual stresses are considered. In the case of the longitudinal residual stress on the upper side of the specimen a residual tensile stress in the base material of $23 \mathrm{~kg} / \mathrm{mm}^{2}$ can be reached, being two thirds of the yield strength of the base material. The stress in transverse direction nearly reaches the same amount in the base material both in tension and compression. The amounts of residual stresses in the bead are even higher. If it is considered that the X-ray elastic constants are altered by plastic deformation ${ }^{5)}$ and are smaller in amount in martensitic structure of steel6), even higher residual stress values are to be expected. But due to change of structure in the bead a higher strength than in the base material is present. It is easy to realize the bearing of the measured stresses on the mechanical properties.

Analytical investigations of welding stresses are of interest. Such calculations have their origin in the temperature field around a fixed point in the weld bead. The knowledge of the thermal stress field around it allows to determine the residual stress state after cooling to ambient temperatures, provided the temperature dependence of thermal expansion coefficient, yield strength and Young's Modulus is known and Hooke's law is satisfied.

In the calculations of Koch and v.d. Bussche ${ }^{8)}$ the temperature field of a line shaped heat source in the center of the bead is implied. After cooling to room temperature the residual stresses in a welded plate can be received when plastic deformation is taken into account. Tensile residual stresses in the bead being compensated by compressive residual stresses at some distance from the bead are the result in good agreement with experiments at arc welded steel plates of 10 and $12 \mathrm{~mm}$ thickness by mechanical methods.

Tall9) uses the temperature field of a moving heat source in order to calculate the residual stresses in single plates edge welded and center welded and in two plates butt welded. Tensile residual stresses in the center of the bead are obtained.

Gorissen ${ }^{10)}$ applies the theory of a moving temperature source to calculate the residual stresses in welded tubes and obtains compressive residual stresses in the bead of a weldment.

The experimental results described here don't fit one of the calculations. In the upper side of the electron beam welded specimen compressive residual stresses in the bead both in longitudinal (Fig. 6) and transverse (Fig. 7) direction are obtained and would fit the latter calculations. In the lower side of the specimen, however, as described, the residual stresses in the longitudinal and transverse direction exhibit opposite signs in the bead (Fig. 8 and Fig. 9).

It must be supposed that the electron beam welded specimen is too thick in shape to fulfill an assumption being inherent in the abstracted theories, namely, that the problem of calculation is a two dimensional one. In the case of the investigated electron beam welded specimen this 
is surely not the case, as the heat input during welding isn't even over the specimens's thickness, the bead of which exhibits a groove angle of about $23^{\circ}$. Therefore, the temperature field, and the temperature stress field cannot be expected to be unchanged over the thickness of the plate. Thus it ins't astonishing that the residual welding stresses can be different both in amount and sign on the upper and lower side of the specimen. Such differences were also obtained in arc welded plates of a plain carbon steel with $0.2 \% \mathrm{C}, 4.5 \mathrm{~mm}$ in thickness and butt welded at a groove angle of $70^{\circ 11}$. The residual stresses obtained by Mathar- and X-ray method in the middle line perpendicular to the bead of the square shaped specimen are shown in Fig. 12 $2^{11)}$ A similar distribution of the residual stresses but of opposite sign is obtained on the upper and lower side of the specimen. The experiments, too, show the outlined influence on the residual welding stresses when an uneven heat input into the bead of a butt welded specimen cccurs.

The author wants to acknowledge the interest and suggestions of Prof. Dr. E. Macherauch.
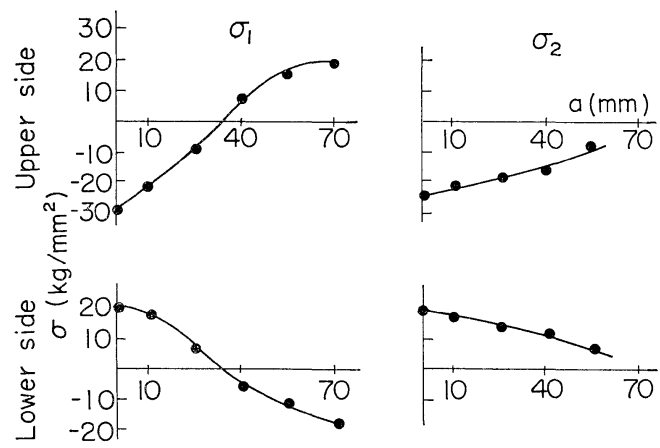

Fig. 12. Residual stresses in longitudinal and transverse direction ${ }^{11)}$ of an arc butt welded steel specimen, $140 \mathrm{~mm}$ square shaped.

\section{References}

1) Mathar, J., Trans. ASME, 56, 249 (1934).

2) Macherauch, E., \& P. Müller, Z. angew. Phys., 13, 361 (1961).

3) Prümmer, R., \& E. Macherauch, Materialprüfung, 8, 281 (1966).

4) Prümmer, R., Diplomarbeit, University Stuttgart (1963).

5) Prümmer, R., Dr. Thesis, University Karlsruhe (1967).

6) Prümmer, R., to be published.

7) Steigerwald, K.H., \& H. Schultz, Schweißen und Schneiden, 18, 592 (1966).

8) Koch, H., \& G.F. v.d. Bussche-Haddenhausen, Schweißen und Schneiden, 17, 189 (1965).

9) Tall, L., Welding Journal, 43, Research Suppl., 10-s (1964).

10) Gorissen, E., Archiv f. Eisenhüttenw., 37, 49 (1966).

11) Murakami, Y., T. Kawabe, \& I. Iwasaki, J. Soc. Mat. Sci., Japan, 13, 984 (1964). 